\title{
HUBUNGAN PENGEMBANGAN KARIER DENGAN KEPUASAN KERJA KARYAWAN PADA PT. SUMBER ALFARIA TRIJAYA Tbk DI BANDAR LAMPUNG
}

\author{
Fahrizi $^{(1)}$, Abdul Naser ${ }^{(2)}$ Edri Aulia Aziz ${ }^{(3)}$ \\ Universitas Sang Bumi Rua Jurai \\ fahrizi@gmail.com,abdulnazar@gmail.com.Edriauliaz2021@gmail.com
}

\begin{abstract}
Abstrak. Pengembangan karier berhubungan dalam menciptakan kepuasan kerja karyawan, pengembangan karier juga merupakan hal yang krusial karena manajemen dapat meningkatkan produktivitas, meningkatkan sikap karyawan terhadap pekerjaannya dan membangun kepuasan kerja yang lebih tinggi. Proses pengembagan karier yang terjadi Pada PT. Sumber Alfaria Trijaya Tbk di Bandar Lampung yaitu belum mencapai hasil yang di inginkan, efek yang diharapkan dari kepuasan kerja yang dimaksud oleh peneliti adalah kepuasan kerja karyawan yang diukur dari beberapa unsur yaitu pengetahuan karyawan tentang tugastugasnya, indikasi kerja yang berkaitan dengan sejauh mana karyawan dapat melaksanakan tanggung jawab kerjanya, keterampilan karyawan dalam memberikan pelayanan kepada konsumen. Dari hasil pengolahan data telah berhasil ditemukan jawaban hipotesis yakni sebagai berikut; terdapat hubungan Pengembangan Karier (X) terhadap Kepuasan Kerja (Y), dengan tingkat pengaruh (R-square) sebesar 47,60\% yang berarti Pengembangan Karier memberikan hubungan sebesar 47,60\% terhadap Kepuasan Kerja. Dari persamaan regresi $\mathrm{Y}=15,514+0,624 \mathrm{X}$ dan ini sesuai dengan hasil persamaan regresi bila Pengembangan Karier di tingkat satuan maka akan menghasilkan Kepuasan Kerja sebesar 0,624 satuan.
\end{abstract}

Kata Kunci: Pengembangan Karier, Kepuasan Kerja

Abstract. Relationship development in creating employee job satisfaction, career development is also crucial because management can increase productivity, improve employee attitudes towards their work and build higher job satisfaction. The career development process that occurs at PT. Sumber Alfaria Trijaya Tbk in Bandar Lampung who have not achieved the desired results, the expected impression of job satisfaction referred to by the researcher is employee job satisfaction which is measured from several elements, namely employee knowledge about their duties, work indications related to the extent to which employees can be carry out job responsibilities, employee skills in providing services to consumers. From the results of data processing, the following hypothesis answers have been found; There is a relationship between Career Development $(X)$ and Job Satisfaction $(Y)$, with a level of influence (R-square) of $47.60 \%$, which means that Career Development has a relationship of $47.60 \%$ on Job Satisfaction. From the regression equation $Y=$ $15.514+0.624 X$ and this is in accordance with the results of the regression equation if Career Development at the unit level will result in Job Satisfaction of 0.624 units.

Keywords: Career Development, Job Satisfaction 


\section{PENDAHULUAN}

Organisasi dikatakan sebagai suatu koordinasi rasional kegiatan sejumlah orang untuk mencapai beberapa tujuan umum melalui pembagian pekerjaan dan fungsi melalui hirarki otoritas dan tanggung jawab. Pekerjaan tidak serta merta merupakan karier, kata pekerjaan (work, job, employment) menunjuk pada setiap kegiatan yang menghasilkan barang atau jasa (Isaacson, 2010); sedangkan kata karier (career) lebih menunjuk pada pekerjaan atau jabatan yang ditekuni dan diyakini sebagai panggilan hidup, yang meresapi seluruh alam pikiran dan perasaan seseorang, serta mewarnai seluruh gaya hidupnya(Winkel 2014)

Karier (Sitompul 2018) merupakan suatu keseluruhan kehidupan seseorang dalam perwujudan diri untuk menjalani hidup dan mencapai tujuan. Untuk mencapai tujuan tersebut, seorang individu harus memiliki kekuatan yang dimiliki seperti penguasaan kemampuan dan aspek yang menunjang kesuksesan karier. Pengembangan karier (Wahyuni, Dwi, Hamidah, N.U., dan Ika 2014) merupakan proses peningkatan kemampuan kerja seseorang yang mendorong adanya peningkatan prestasi kerja dalam rangka mencapai karier yang diinginkan Program pengembangan karier sangat penting dilakukan karena untuk menyesuaiakan antara kebutuhan dan tujuan karyawan dengan kesempatan karier yang tersedia di perusahaan saat ini maupun di masa mendatang
Menurut Mangkuprawira yang dikutip oleh (Joni and Parela 2020) pengembangan karir meliputi kegiatankegiatan personalia yang dilakukan untuk mencapai sebuah rencana karier. Untuk beberapa orang, pekerjaan-pekerjaan tersebut sebagai bagian dari sebuah perencanaan yang disiapkan secara terarah sedangkan untuk yang lainnya bisa jadi sebuah karir dikatakan sebagai peristiwa keberuntungan.

Maka dari itu pemilihan karier lebih memerlukan persiapan dan perencanaan yang matang dari pada kalau sekedar mendapat pekerjaan yang sifatnya sementara waktu.

Pengembangan karir (Supardi 2016)berpusat pada sekitar kebutuhan yang dihubungkan dengan kegiatan dan minat karyawan. Pengembangan karir menunjukkan adanya peningkatanpeningkatan status seseorang dalam jalur karir yang telah ditetapkan. Sehingga dengan adanya pengembangan karir ini dapat memberikan dorongan kepada karyawan dalam mengembangkan karir dalam pekerjaannya dengan cara meningkatkan pengetahuan, sikap dan keterampilan. Dengan demikian dengan adanya pengembangan karir akan memberi kepuasan kerja bagi karyawan itu sendiri.

Berdasarkan penelitian sebelumnya tentang (Harahap and Si 2017) bahwa faktor-faktor faktor-faktor yang mempengaruhi kepuasan kerja antara lain:

\section{Pay satisfaction}

Sebagian besar karyawan merasa kurang puas dengan gaji yang mereka terima saat ini. Sebagian karyawan puas dengan gajinya karena sudah memenuhi 
kecukupan minimum dari kebutuhan hidup mereka.

2. Promotion satisfaction

Pelaksanaan kebijakan perusahaan tidak selalu konsisten padahal dulunya perusahaan selalu konsisten dengan kebijakan tersebut.

3. Supervision satisfaction

Kemampuan dan keahlian para atasan di perusahaan ini tergolong baik tetapi tidak semua atasan di perusahaan ini merupakan komunikator yang baik.

4. Coworker satisfaction

Sisi positif yang dimiliki sejumlah karyawan antara lain mau bekerja sama dan mau menolong rekannya ketika dalam kesulitan. Sementara itu, sisi negatif yang dimiliki beberapa rekan lainnya antara lain sikap acuh tak acuh dan mementingkan diri sendiri.

5. Satisfaction with the work itself Untuk pekerjaan dalam kantor, sifatnya lebih monoton dan membosankan, sedangkan untuk pekerjaan lapangan lebih ada tantangannya dan tingkat kesulitannya juga lebih tinggi.

Selanjutnya menurut penelitian (Sari and Hadijah 2016) bahwa untuk meningkatkan kinerja pegawai, harus memperhatikan kepuasan kerja yang dirasakan oleh pegawai serta meningkatkan disiplin kerja dengan memberikan stimuli kepada pegawai.

Keberadaan pengembangan karier juga diperlukan oleh setiap karyawan untuk meningkatkan komitmen kerja sumber daya manusia. Halmard (2008:24) menyatakan bahwa organisasi yang maju dan berkembang identik dengan pengembangan karier. Hans (2007:39) menyatakan pengembangan karier memberikan pengaruh langsung terhadap komitmen sumber daya manusia. Phoobe dan Steband (2007:140) menyatakan pengembangan karier dalam suatu organisasi identik dengan peningkatan pendidikan, pelatihan, mutasi kerja dan promosi jabatan.

Pengembangan karier memiliki eksistensi yang sangat besar bagi perusahaan swasta maupun pemerintahan dikarenakan pengembangan karir merupakan tolak ukur bagi karyawan didalam melakukan pembinaan karirnya. Apabila perusahaan swasta ataupun pemerintahan tidak melakukan pengembangan karir maka perusahaan ataupun pemerintahan tidak akan dapat melakukan peningkatan pembinaan karir.

Pengembangan karier tidak hanya berhubungan dengan karakteristik organisasi saja tetapi berhubungan juga dengan karakteristik individu dan disiplin kerja. Individu yang merencanakan dan organisasi yang mengarahkan. Pengembangan karir karyawan adalah pendekatan atau kegiatan yang tersusun secara formal untuk meningkatkan pertumbuhan, kepuasan kerja, pengetahuan, dan kemampuan karyawan agar organisasi dapat memastikan bahwa orang-orang dengan kualifikasi dan pengalaman yang cocok tersedia dalam organisasi. Dalam dunia pekerjaan, unsur yang paling dibutuhkan adalah pembentukkan karakteristik karyawan karena pembentukkan karakteristik merupakan pikiran yang di dalamnya terdapat seluruh program yang terbentuk dari pengalaman hidupnya (karyawan) merupakan pelopor segalanya. Program ini kemudian membentuk sistem kepercayaan yang akhirnya dapat membentuk pola berpikirnya yang bisa mempengaruhi perilakunya.

Di mana penelitian terdahulu di lakukan oleh Ita Rifani Permatasari (2006) adanya pengaruh signifikan antara pengembangan karir terhadap kepuasan 
kerja karyawan. Maka dari hasil penelitian terdahulu dapat di ambil kesimpulan saling berpengaruh dan saling berhubungan antara karakteristik organisasi, karakteristik individu dan disiplin kerja karyawan terhadap pengembangan karier, yang mana pengembangan karier karyawan adalah suatu pendekatan atau kegiatan yangtersusun secara formal untuk meningkatkan pertumbuhan, kepuasan kerja,pengetahuan, dan kemampuan karyawan agar organisasi dapat memastikan bahwa orang-orang dengan kualifikasi dan pengalaman yang cocok tersedia dalamorganisasi dapat membantu perkembangan perusahaan.

Meningkatkan kepuasan kerja sumber daya manusia dapat dilakukan melalui penerapan kepuasan kerja yang mendukung tercapainya maksud dan tujuan perusahaan untuk dapat terus berkembang dan bertahan dalam kurun waktu yang lama, sehingga nilai dan manfaatnya langsung ataupun tidak langsung dapat dirasakan oleh pemegang saham, konsumen, serta masyarakat luas (Mangkunegara, 2007 : 12).

Menurut Robbins kepuasan kerja merupakan sikap secara umum yang lebih diwarnai oleh perasaan terhadap situasi dan lingkungan kerja serta merupakan pencerminan dari kepuasan seorang karyawan terhadap kondisi yang berkaitan dengan pelaksanaan pekerjaan. (Robbins, 2009 : 208).

Tindak lanjut penilaian kepuasan kerja akan memungkinkan karyawan mendapat promosi mutasi, demosi, pelatihan dan pengembangan lebih lanjut,atau balas jasanya dinaikan. Kepuasan kerja ini penting bagi karyawan dan berguna bagi perusahaan untuk menetapkan kebijaksanaan selanjutnya.
Berdasarkan studi lapangan proses pengembangan karier yang terjadi pada PT. Sumber Alfaria Trijaya Tbk di Bandar Lampung itemukan fakta bahwa belum mencapai hasil yang di inginkan, masih banyak karyawan yang bekerja dengan tidak berorientasi kepada peningkatan kemampuan dan karier serta terkesan enggan untuk mengemban tanggung jawab yang lebih besar dan kurangnya pengetahuan mengenai tupoksi pekerjaan yang diemban dan karier yang seolah-olah jalan ditempat. Dan dirasa masih kurang berkembang.

Hal ini dikarenakan berkaitan dengan permasalahan prestasi kerja karyawan, yaitu disiplin kerja yang rendah, dapat dilihat dalam hal mentaati peraturan masuk kerja dan waktu keluar kerja, banyaknya karyawan yang tidak mengikuti apel pagi, serta penggunaan jam kerja yang kurang efektif. Selain itu permasalahan prestasi terletak pada kurangnya kemampuan pemahaman karyawan terhadap tugas. Hal ini berakibat karier yang dibangun menjadi kurang maksimal bekerja hanya sebatas memenuhi kewajiban dan kebutuhan hidup.

Berdasarkan permasalahan tersebut, maka perlu untuk mencari hubungan antara pengembangan karier dengan kepuasan kerja karyawan.

\section{METODE PENELITIAN}

Penelitian ini bertujuan untuk untuk mengetahui hubungan pengembangan karier terhadap kepuasan kerja karyawan. Oleh karena itu penelitian ini menggunakan metode penelitian metode Penelitian Deskriptif, yang menggunakan penelitian lapangan (field reseach), bersifat kuantitatif dimana penjelasannya 
bersifat objektif dengan menjelaskan pendekatan-pendekatan yang ada.

Data yang diperlukan dalam penelitian dapat berupa data sekunder dan data primer yang dikumpulkan dengan cara sebagai berikut :

a. Data Primer

Pengumpulan data primer dilakukan melalui survey ke lapangan secara langsung yang disertai dengan wawancara secara terbuka yang dilakukan dengan karyawan pada PT. Sumber Alfaria Trijaya Tbk Di Bandar Lampung.

b. Data Sekunder

Mencatat data-data yang dipublikasikan oleh PT. Sumber Alfaria Trijaya Tbk Di Bandar Lampung dalam bentuk aplikasi dilapangan yang sifatnya berkala (time series).

Penelitian ini dilakukan secara langsung ke PT. Sumber Alfaria Trijaya Tbk Di Bandar Lampungdengan langkahlangkah :

a. Observasi, yaitu pengamatan langsung guna menguji kebenaran hasil wawancarayang telah dilakukan sebelumnya hingga diperoleh bukti dan fakta empiris dari instansi tersebut.

b. Wawancara, dilakukan dengan cara bertemu langsung dan bertanya secara langsung dengan karyawan PT. Sumber Alfaria Trijaya Tbk Di Bandar Lampung.

c. Kuesioner, yaitu melakukan penyebaran daftar pertanyaan yang diajukan kepada karyawan PT. Sumber Alfaria Trijaya Tbk Di Bandar Lampung.

d. Dokumentasi, yaitu merupakan teknik pengumpulan data yang dilakukan dengan cara mencari data mengenai hal-hal yang berhubungan dengan penelitian.

Menurut Arikunto, apabila subjeknya kurang dari 100 orang, lebih baik di ambil semua sehingga penelitiannya merupakan penelitian populasi. Selanjutnya jika subjeknya besar atau lebih dari 100 orang maka dapat diambil antara $10-15 \%$ atau $20-25 \%$ atau lebih. (Arikunto, 2008: 120).

Populasi dalam penelitian ini adalah seluruh karyawan PT. Sumber Alfaria Trijaya Tbk Di Bandar Lampungyaitu sebanyak 150 karyawan, dan berdasarkan ukuran di atas, maka sampel dalam penelitian ditentukan sebanyak 30 orang atau $20 \%$ dari seluruh populasi. Adapun teknik sampling yang digunakan adalah simple random sampling. yaitu pengambilan sampel secara acak, dan semua sampel memiliki proporsi yang sama.

Pengolahan data dilakukan dengan tahapan sebagai berikut:

1. Editing data, adalah tindakan menyusun dan menentukan kembali data yang diperoleh,sehingga dapat dipersiapkan untuk proses pengolahan lebih lanjut.

2. Interpretasi data, yaitu tindakan untuk mendeskripsikan,sehingga dapat dilakukan penarikan kesimpulan atas hasil penelitiaan dan pembahasan yang dilakukan.

Instrumen dapat dikatakan reliabel bila memiliki koefisien kehandalan reliabilitas sebesar 0,6 atau lebih. (Uyanto.2006:50). Penghitungan instrumen penelitian (validitas dan reliabilitas), menggunakan alat bantu program statistika PASW version 18.

Untuk menguji secara hipotesis secara parsial digunakan Uji $\mathrm{t}$ dengan rumus : 


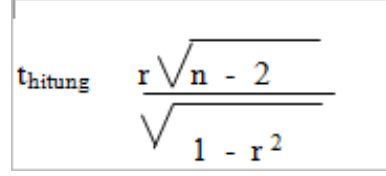

Dimana :

$$
\begin{array}{ll}
\mathrm{t}_{\text {hitung }} & =\text { Nilai } \mathrm{t} \\
\mathrm{r} & =\text { Koefisien Korelasi } \\
\mathrm{n} & =\text { Jumlah responden }
\end{array}
$$

( Sugiyono, $2008: 230$ )

Kriteria untuk Uji $\mathrm{t}$ adalah sebagai berikut :

a) Jika thitung $>t_{\text {tabel }}$ maka Ha diterima dan Ho ditolak.

b) Jika thitung $\leq t_{\text {tabel }}$ maka Ha ditolak dan Ho diterima.

Taraf signifikan dalam penelitian ini digunakan $\alpha=0,05$ atau 5\%.

Yang dimaksud dengan Hipotesis nol (Ho) dan Hipotesis alternatif (Ha) adalah

Ho $=\mathrm{r}_{1} \leq 0$

Berarti tidak ada hubungan antara pengembangan karier terhadap kepuasan kerja karyawan.

$\mathrm{Ha}=\mathrm{r}_{1}>0$

Berarti ada hubungan antara pengembangan karier terhadap kepuasan kerja karyawan.

\section{HASIL DAN PEMBAHASAN}

Dari hasil di atas dihasilkan data dengan cara menguraikan data tersebut dalam bentuk kalimat secara terperinci dan sistematik. Berdasarkan data yang disajikan pada bab terdahulu, kemudian data tersebut dianalisa dalam upaya penulisan skripsi, hal ini dimaksudkan untuk membuktikan dan menjawab hipotesis yang disajikan. Selanjutnya dari hasil penelitian dengan penyetoran angket dapat diluhat dari jawaban responden.

Untuk mengetahui pengembangan karier maka dapat dilihat melalui angket yang telah disebar yaitu dengan menggunakan pertanyaan langsung kepada responden dengan menyebarkan angket berjumlah 10 item/pertanyaan, berdasarkan tabulasi data dari variabel pengembangan karier dapat diketahui nilai tertinggi 20 dan nilai terendah 2 sehingga angka-angka tersebut dipakai untuk membuat pengklasifikasian. Dalam hal ini diklasifikasikan ke dalam 3 kategori yaitu tinggi, sedang dan rendah. Responden dengan jawaban 2-6 : Rendah.

Responden dengan jawaban $7-11$ :

Sedang.

Responden dengan jawaban $12-20$ : Tinggi.

Penulis menjelaskan dengan analisa kualitatif mengenai pengembangan karier pada PT. Sumber Alfaria Trijaya Tbk Di Bandar Lampungprosedur kepuasan kerja dan sumber daya manusia.

Dibawah ini akan disajikan tabel Rekapitulasi Jawaban Responden Tentang Kepuasan Kerja.

\begin{tabular}{|c|c|c|c|}
\hline No & Alternatif Jawaban & Frekuensi & $\%$ \\
\hline 1 & Rendah $2-6$ & 2 & $4,55 \%$ \\
\hline 2 & Sedang $7-11$ & 2 & $4,55 \%$ \\
\hline 3 & Tinggi $12-20$ & 26 & $90,90 \%$ \\
\hline & Jumlah & 30 & $100 \%$ \\
\hline
\end{tabular}

Tabel 1.

Jawaban Responden Tentang Kepuasan Kerja

Sumber: $\quad$ PT. Sumber Alfaria Trijaya Tbk Di Bandar Lampung, 2020 
Berdasarkan tabel di atas menunjukkan bahwa tanggapan responden tentang kepuasan kerja tinggi sebanyak 26 responden $(90,90 \%)$, yang menyatakan sedang sebanyak 2 orang $(4,55 \%)$, dan yang menyatakan rendah sebanyak 2 orang (4,55\%). Dengan demikian dapat disimpulkan bahwa kepuasan kerja sudah cukup baik dan perlu ditingkatkan lagi.

Dengan menggunakan rumus korelasi product moment dengan taraf signifikan $5 \%$, maka dapat nilai :

$$
\begin{aligned}
& r_{x y}=\frac{30 \times 31248-1164 \times 117}{\sqrt{\left(35 \times 30954-(1164)^{2}\right\}}\left\{35 \times 31734-(1176)^{2}\right\}} \\
& r_{x y}=\frac{1374912-1370028}{\sqrt{\{131976-1354890)}\{1398540-1385329\}}
\end{aligned}
$$$$
r_{x y}=\frac{4984}{\sqrt{(7086)(13211)}}
$$$$
r_{x y}=\frac{4984}{9675}=0,5114
$$

Dengan demikian karena $r$ hitung lebih besar darir tabel, maka dapat dikatakan bahwa hubungan pengembangan karier terhadap kepuasan kerja pegawai pada PT. Sumber Alfaria Trijaya Tbk Di Bandar Lampung berhubungan positif dan signifikan.

Kemudian untuk mengetahui keeratan hubungan antara variabel $\mathrm{X}$ terhadap variabel $\mathrm{Y}$, maka dapat dilihat dari $\mathrm{r}$ hitung dikonsultasikan dengan tabel daftar interpretasi di bawah ini :
Interpretasi keeratan Hubungan

\begin{tabular}{cc}
\hline Besarnya Nilai & Interpretasi \\
\hline Antara $0,800-$ & Sangat Tinggi \\
1,000 & Tinggi \\
Antara $0,600-$ & \\
0,800 & Sedang \\
Antara $0,400-$ & \\
0,600 & Rendah \\
Antara $0,200-$ & \\
0,400 & Sangat Rendah \\
Antara $0,000-$ & \\
0,200 & \\
Sumber : Suharsimi Arikunto, 2013
\end{tabular}

Berdasarkan konsultasi yang dilakukan pada $r$ tabel tersebut maka ternyata $r$ hitung $=0,5114$ terletak antara $0,400-0,600$ termasuk sedang.

Untuk mengetahui besarnya hubungan antara pengembangan karier terhadap kepuasan kerja dapat dihitung dengan rumus Koefisien Determinasi (KD). Dengan demikian hubungan antara pengembangan karier terhadap kepuasan kerja pada PT. Sumber Alfaria Trijaya Tbk Di Bandar Lampungdapat digunakan rumus Koefisien Determinasi (KD), yaitu:

$$
\begin{aligned}
\mathrm{KD} & =r^{2} \times 100 \% \\
& =0,5114^{2} \times 100 \% \\
& =0,2615 \times 100 \% \\
& =26,15 \%
\end{aligned}
$$

Dengan demikian pengembangan karier terhadap kepuasan kerja pada PT. Sumber Alfaria Trijaya Tbk Di Bandar Lampung mempunyai hubungan $26,15 \%$ dan sisanya sebesar $75,85 \%$ dipengaruhi oleh faktor lain.

Untuk mengetahui apakah hipotesis yang diajukan atau tidak, untuk itu penulis menggunakan uji $t$, dimana diperoleh $r$ sebesar 0,51 maka nilai $\mathrm{t}$ hitung adalah sebagai berikut :

$\mathrm{t}$ tes $=r \sqrt{\frac{n-2}{1-r^{2}}}$

Tabel 2. 


$$
\begin{aligned}
& \mathrm{t} \text { tes }=0,5114 \sqrt{\frac{30-2}{1-(0,5114)^{2}}} \\
& \mathrm{t} \text { tes }=0,5114 \sqrt{\frac{28}{1-0,61}} \\
& \mathrm{t} \text { tes }=0,5114 \sqrt{\frac{28}{0,739}} \\
& \mathrm{t}=0,5114 \times 7,538
\end{aligned}
$$

Dari perhitungan di atas dapat diperoleh $\mathrm{r}$ hitung sebesar $\mathrm{t}=3,85$ sedangkan $\mathrm{r}=$ tabel pada taraf signifikan atau $\alpha 0,05$ sebesar $\mathrm{t}=2,021$ dan $\mathrm{t}$ tabel pada taraf signifikan $1 \%$ atau $\alpha$ sebesar 2,704, maka dengan demikian t hitung lebih besar dari t tabel.

\begin{tabular}{cc}
\hline Besarnya Nilai & Interpretasi \\
\hline Antara 0,800 $-\mathbf{1 , 0 0 0}$ & Sangat Tinggi \\
Antara 0,600 $-\mathbf{0 , 8 0 0}$ & Tinggi \\
Antara 0,400 $-\mathbf{0 , 6 0 0}$ & Sedang \\
Antara 0,200 $-\mathbf{0 , 4 0 0}$ & Rendah \\
Antara 0,000 $-\mathbf{0 , 2 0 0}$ & Sangat Rendah \\
\hline Sumber : Suharsimi Arikunto, 2013
\end{tabular}

Setelah mengetahui hasil data tersebut, maka didasarkan dengan ketentuan dengan penerimaan dan penolakan hipotesis yang kemungkinan sebelumnya, yaitu:

1. Ho ditolak jika ternyata $t$ hitung lebih besar dari $\mathrm{t}$ tabel.

2. Ho diterima jika ternyata $t$ hitung lebih kecil dari $t$ tabel

3. Jika dalam analisis Ho ditolak, maka hipotesis kerja diterima dan terdapat hubungan.

Berdasarkan ketentuan tersebut, maka hipotesis nihil (Ho) ditolak karena t hitung $=3,85$ lebih besar dari $\mathrm{t}$ tabel $=2,021$. Hal ini berarti bahwa terdapat hubunganyang positif antara pengembangan karier terhadap kepuasan kerja karyawan.
Dari uraian tersebut di atas dapat disimpulkan bahwa, hipotesis yang dipergunakan dalam penelitian ini adalah pengembangan karier mempunyai hubungan yang positif dalam usaha meningkatkan kepuasan kerja karyawan pada PT. Sumber Alfaria Trijaya Tbk Di Bandar Lampungdapat diterima.

Berdasarkan hasil penelitian di atas, maka diperoleh Koefisien Determinasi pengembangan karier terhadap kepuasan kerja karyawan adalah sebagai berikut :

Tabel 2. Koefisien Determinasi Pengembangan karier terhadap Kepuasan Kerja.

\begin{tabular}{|c|c|r|r|c|}
\hline Model & $\mathrm{R}$ & $\mathrm{R}$ Square & $\begin{array}{c}\text { Adjusted } \mathrm{R} \\
\text { Square }\end{array}$ & $\begin{array}{c}\text { Std. Error of the } \\
\text { Estimate }\end{array}$ \\
\hline 1 &, $690^{\mathrm{a}}$ &, 476 &, 458 & 2,94221 \\
\hline
\end{tabular}

a. Predictors: (Constant), $\mathrm{X}$

Koefisien Determinasi $(\mathrm{KD})=\mathrm{R}^{2}=$ $0,476=0,476 \times 100 \%=47,60 \%$. Dapat disimpulkan bahwa variabel pengembangan karier (X) menjelaskan variasi perubahan variabel kepuasan kerja karyawan (Y) sebesar 47,60\%, sedangkan sisanya dijelaskan oleh faktor lain yang tidak dikaji dalam penelitian ini.

Berdasarkan hasil penelitian, maka diperoleh data hubungan pengembangan karier (X) terhadap kepuasan kerja (Y) sebagai berikut :

Tabel 3. Uji Hipotesis Hubungan Pengembangan karier terhadap Kepuasan Kerja

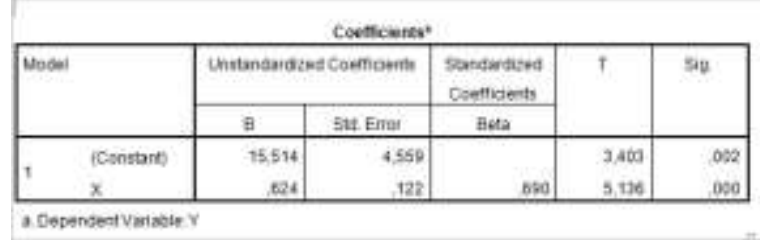

Berdasarkan hasil Uji t didapat nilai $t_{\text {hitung }}=5,136$. Apabila dibandingkan dengan $t_{\text {tabel }}$ pada taraf signifikan yaitu 1,690 , maka $t_{\text {hitung }}=5,136>\mathrm{t}_{\text {tabel }}=1,690$, sehingga dapat disimpulkan bahwa; 
Hipotesis yang menyatakan terdapat hubungan antara Variabel Pengembangan karier (X) terhadap Kepuasan Kerja Karyawan (Y) Pada PT. Sumber Alfaria Trijaya Tbk Di Bandar Lampungdapat diterima. Jadi variabel Pengembangan karier berhubungan terhadap variabel Kepuasan Kerja Karyawan (Y) pada PT. Sumber Alfaria Trijaya Tbk Di Bandar Lampung.

\section{KESIMPULAN}

Berdasarkan hasil penelitian dan pembahasan yang sudah dilakukan maka dapat disimpulkan bahwa pengembangan karier mempunyai hubungan yang signifikan terhadap kepuasan kerja. ini dapat dilihat dari nilai koefisiensi determinasi $\left(\mathrm{R}^{2}\right)$ variabel pengembangan karier terhadap kepuasan kerja karyawan sebesar 0,476. Hal ini menunjukkan bahwa hubungan pengembangan karier terhadap kepuasan kerja karyawan sebesar $47,60 \%$ dan sisanya dipengaruhi oleh faktor lain.

Dari analisis diperoleh koefisien korelasi atau $\mathrm{t}$ hitung $=5,136$ sedangkan $\mathrm{t}$ tabel dengan taraf signifikan 1,690 dengan demikian $\mathrm{t}$ hitung lebih besar dari ttable $5,136>1,690$.Hal ini Untuk mengetahui analisis tersebut, maka dapat diketahui dengan menggunakan koefisien penentu $\left(\mathrm{r}^{2}\right)$ dengan nilai $47,60 \%$, dengan ini pengembangan karier mempunyai hubungan terhadap kepuasan kerja karyawan pada PT. Sumber Alfaria Trijaya Tbk Di Bandar Lampung sebesar 47,60\%, sedangkan selebihnya dipengaruhi oleh faktor lain yang tidak diteliti.

Berdasarkan analisis dengan menggunakan Koefisien Determinasi (KD) berarti terdapat hubungan yang positif dan signifikan antara pegembangan karier dengan kepuasan kerja karyawan pada PT.
Sumber Alfaria Trijaya Tbk Di Bandar Lampung.

DAFTAR PUSTAKA

Harahap, Ramadhan, and M. Si. 2017. "ANALISA KEPUASAN KERJA KARYAWAN DI CV. REZEKI MEDAN." 8(2):6.

Joni, Rafian, and Epi Parela. 2020. "DAMPAK PENGEMBANGAN KARIR DAN BUDAYA KERJA TERHADAP KINERJA APARATUR SIPIL NEGARA (ASN) PADA DINAS PERHUBUNGAN PROVINSI LAMPUNG.” 6(2):121-28.

Sari, Ririn Nur Indah, and Hady Siti Hadijah. 2016. "Peningkatan Kinerja Pegawai Melalui Kepuasan Kerja Dan Disiplin Kerja." Jurnal Pendidikan Manajemen Perkantoran 1(1):204. doi: 10.17509/jpm.v1i1.3389.

Sitompul, Lenia. 2018. "Meningkatkan Pemahaman Perencanaan Karir Melalui Layanan Bimbingan Karir Di Sekolah Dengan Menggunakan Media Gambar Pada Siswa Kelas Ix-1 Smp Negeri 1 Gebang Tahun 2017-2018." Jurnal Tabularasa PPS UNIMED 51(1):51.

Supardi, Endang. 2016. "Pengembangan Karir Kontribusinya Terhadap Kinerja Pegawai.” Jurnal Geografi Gea 9(1). doi: 10.17509/gea.v9i1.1680.

Wahyuni, Dwi, Hamidah, N.U., dan Ika, R. 2014. "PENGARUH PENGEMBANGAN KARIER TERHADAP PRESTASI KERJA KARYAWAN." Jurnal Administrasi Bisnis (JAB) 8(1):110. 
Fahrizi : Hubungan Pengembangan Karier Dengan Kepuasan Kerja Karyawan Pada Pt. Sumber Alfaria Trijaya Tbk Di Bandar Lampung

Winkel, W. S. 2014. Psikologi

Pengajaran.Winkel, W.S. (2014).

Jakarta:Grasindo. Jakarta: Grasido. 